\title{
Açóes de prevençáo e controle do tabagismo em ambiente escolar no município de Pinheiro, Maranhão
}

Prevention and control of smoking in the school environment in the municipality Pinheiro, State of Maranhão, Brazil

\section{RESUMO}

Relato de experiência resultante do projeto de extensão "Programa de prevenção e combate ao tabagismo no ambiente escolar no Município de Pinheiro-MA", desenvolvido por docentes e discentes da Universidade Federal do Maranhão. O projeto teve como objetivo, a implantação de um programa de prevenção e combate ao tabagismo no ambiente escolar no município maranhense de Pinheiro que discutiu a problemática das drogas, focando no uso do tabaco e contribuindo com a troca de conhecimentos e prevenção do tabagismo no ambiente escolar. Foram desenvolvidas cinco etapas: apresentação para os parceiros; sensibilização dos diretores, professores, pais/responsáveis; sensibilização dos alunos; atividades complementares; avaliação pela equipe e divulgação dos resultados. Durante os meses de março a junho de 2016, participaram das atividades desenvolvidas pelo projeto, aproximadamente 350 alunos. Os resultados demonstraram a importância da integração ensino-pesquisa-extensão, além de evidenciarem que a intervençáo no ambiente escolar é um potente influenciador para a adoçáa de um estilo saudável de vida e que as questôes relacionadas às drogas estấo presentes na vida e no imaginário das crianças e adolescentes.

Palavras-chave: Tabagismo. Saúde escolar. Adolescente. Campanhas.

\section{ABSTRACT}

Report of experience resulting from the extension project "Program for preventing and combating smoking in the school environment in the Municipality of Pinheiro-MA", developed by teachers and students of the Federal University of Maranhão, State of Maranhão, Brazil. The project aimed to implement a program to prevent and combat smoking in the school environment in the municipality of Pinheiro, State of Maranhão, Brazil which discussed the drug problem, focusing on the use of tobacco, contributing to the exchange of knowledge and prevention of smoking in the school environment. Five steps were
Ariane Cristina Ferreira Bernardes Neves

Doutoranda em Saúde Coletiva na Universidade Federal do Maranhão, Brasil; professora assistente do curso de Medicina na mesma instituição (ariane_bernardes@hotmail.com).

Maria dos Remédios da Silva Lira

Mestrado profissional em Saúde da Família pela Rede Nordeste de Saúde da Família, Nucleadora Universidade Federal do Maranhão; professora do curso de Enfermagem na mesma instituiçãoo (marialira01@yahoo.com.br).

Diogo Pereira de Carvalho

Graduando em Medicina na Universidade Federal do Maranhão, Brasil (drdiogo30@gmail.com).

Roberto Mendes Filho

Graduando em Enfermagem na Universidade Federal do Maranhão, Brasil (rmendespm@hotmail.com). 
developed: presentation to partners; awareness of principals, teachers, parents/guardians; student awareness; Additional activities; evaluation by the team and dissemination of results. During March and June 2016, approximately 350 students participated in the activities developed by the project. The results demonstrated the importance of teaching-research-extension integration, as well as evidence that intervention in the school environment is a powerful influence on the adoption of a healthy lifestyle and that drug-related issues are present in the life and imagination of children and adolescents.

Keywords: Tobacco use disorder. School health. Adolescent. Campaigns.

\section{INTRODUÇÃO}

O uso de tabaco é a principal causa evitável de morte e doenças no mundo (JHA P; PETO, 2014). Aproximadamente, 80\% dos fumantes vivem em países com renda baixa e/ou média, onde a carga das doenças relacionadas ao tabaco tem grande impacto (WHO, 2017).

O tabagismo é um fator de risco modificável e a grande maioria dos fumantes inicia tal hábito ainda na adolescência. No Brasil, a Pesquisa Nacional de Saúde do Escolar (PeNSE) documentou que $30 \%$ dos jovens entre 13 e 15 anos começaram a fumar antes dos 12 anos de vida (BARRETO et al., 2014). É nessa fase que ocorre a maior exposição aos comportamentos de risco, sendo considerada como uma fase de experimentaçóes em decorrência das descobertas, das inquietaçóes, da necessidade de explorar o desconhecido e de se aventurar sem preocupaçôes com as consequências, incluindo nesta iniciação o cigarro (SMALLEY; WITTLER; OLIVERSON, 2004).

Entende-se que nem todos os adolescentes que experimentam cigarros se tornam fumantes, porém, a experimentação é o primeiro passo para uma futura adesão ao consumo regular de tabaco (BORRACI, 2015). O início do tabagismo, em idade precoce, está associado ao aumento da chance de uso de outras substâncias psicoativas (SPAs), como o álcool e drogas ilícitas. Assim, um ponto chave na saúde pública é prevenir e combater a iniciação deste hábito. Os programas que utilizam estratégias de prevenção baseadas em conceitos de influência social, competências de vida e que envolvem níveis elevados 
de interatividade com sessóes de reforço representam, provavelmente, o meio mais adequado para lidar com esse problema. Aliado a isso, os programas em contexto escolar parecem constituir abordagens eficazes para prevenir o consumo de tabaco, álcool e maconha nos jovens (SANTANA et al. 2016).

Por esse motivo, ao longo das últimas décadas, o ambiente escolar tem sido foco de esforços particulares para influenciar o comportamento dos adolescentes com intervençóes competentes que os ajudem a evitar o uso de tabaco, principalmente nessa etapa tão precoce de suas vidas (IBGE, 2016; FIGUEREDO et al., 2016).

Além disso, o Programa Saúde na Escola (PSE), do Ministério da Saúde e do Ministério da Educação, instituído desde 2007, fruto do esforço em construir políticas intersetoriais, aponta o ambiente escolar como espaço privilegiado para práticas promotoras da saúde, prevenção e de educação para saúde. Entre as açóes de saúde previstas para serem desenvolvidas no âmbito escolar, consideradas atividades de promoção e prevenção à saúde, encontra-se a prevenção ao uso de álcool, tabaco e outras drogas (BRASIL, 2011; 2015).

Levando-se em consideração a relevância das ações da relação ensinoserviço-comunidade como contribuição acadêmica para o Sistema Único de Saúde (SUS), faz-se necessário ampliar a discussão no escopo das ações de prevenção e controle do tabagismo entre crianças e adolescentes no ambiente escolar.

Em virtude dos fatos já mencionados, esse estudo teve como objetivo, relatar a experiência acadêmica com adolescentes de uma escola pública, através do projeto de extensão sobre prevenção e controle do tabagismo no ambiente escolar.

\section{DESENVOLVIMENTO}

Estudo descritivo, tipo relato de experiência, produzido a partir do projeto de extensão "Programa de prevenção e combate ao tabagismo no ambiente escolar no Município de Pinheiro, Maranhão", desenvolvido, em uma escola pública de um município da baixada maranhense, por acadêmicos e docentes do Curso de Graduação em Medicina e Enfermagem do Centro de Ciências Humanas, Naturais, 
Saúde e Tecnologia de Pinheiro, da Universidade Federal do Maranhão (UFMA), e por um Agente Comunitário de Saúde (ACS) da Unidade Básica de Saúde (UBS) próxima à escola, no ano de 2016.

O projeto de extensão teve como objetivo geral sensibilizar e capacitar os professores, diretores e alunos dessa escola, bem como seus pais e responsáveis, para o enfrentamento do uso do tabaco, com ênfase em seus malefícios, por intermédio de ações de promoção à saúde e prevenção de agravos. Como objetivo específico o projeto visou incentivar os alunos à adoçáo de posturas e hábitos que valorizassem uma vida saudável, enriquecendo o currículo escolar com atividades práticas e teóricas na exploração do tema transversal "Educação antidrogas - tabagismo".

É importante ressaltar que o projeto contou com financiamento da Fundação de Amparo à Pesquisa e ao Desenvolvimento Científico e Tecnológico do Maranhão (FAPEMA) e que foi desenvolvido em quatro meses, percorrendo o itinerário metodológico em etapas.

$\mathrm{Na}$ primeira etapa, a equipe organizadora elegeu a escola na qual o projeto seria desenvolvido, levando-se em consideraçáo a proximidade com a Unidade Básica de Saúde onde ocorriam as aulas práticas dos alunos da universidade. Em seguida, fez-se o contato com a escola eleita, através de visita à instituição, momento em que foi entregue e apresentado o projeto para a direçáo escolar.

Vale ressaltar que houve uma boa receptividade e interesse no desenvolvimento do projeto por parte da escola. Dessa forma, definiuse, em seguida, que as atividades seriam realizadas com os alunos do $6^{\circ}$ ao $9^{\circ}$ ano do ensino fundamental, do turno vespertino, que estavam na faixa etária entre 11 e 15 anos, totalizando 350 alunos, distribuídos em 10 salas de aula.

Convém lembrar que a escolha da faixa etária ocorreu levando-se em consideraçáo que os educandos compóem a faixa etária de alunos em fase crítica para determinação da conduta em relação à saúde, seja com adoção de um estilo de vida saudável ou com vícios nocivos à saúde, uma vez que pesquisas confirmam a importância da identificação de abordagens em educação e saúde com conteúdos que promovam práticas de prevençáo de vários agravos, nas faixas etárias em que os vícios ou comportamentos de risco ainda não foram adquiridos 
(BUCHELE; COELHO; LINDNER, 2009; BARANKIN, 2013).

As demais etapas foram executadas pelos acadêmicos dos cursos de medicina e enfermagem, com apoio do ACS, que atuou como agente mobilizador e multiplicador de conhecimentos profissionais, todos supervisionados pelas docentes e coordenadoras do projeto.

É de suma importância mencionar que foi realizada revisão de literatura e estudo sobre o tema "Tabagismo", em especial, nos adolescentes em idade escolar, a fim de subsidiar as açôes educativas das etapas subsequentes.

A segunda etapa teve como objetivo sensibilizar o público envolvido: gestores e professores que estiveram presentes na escola durante todos os dias, bem como a comunidade externa que se fez presente, principalmente, nas reuniốes realizadas para os pais e responsáveis. Essa etapa foi realizada em dois momentos.

O primeiro momento aconteceu durante a semana de planejamento pedagógico da escola, contando, inclusive, com a participação de uma coordenadora pedagógica e quinze professores do turno vespertino, correspondendo a $70 \%$ dos professores desse turno e $100 \%$ da coordenação pedagógica. A equipe de execuçáo do projeto fez uma explanação sobre a temática (tabagismo) e a relevância da abordagem no ambiente escolar e também apresentou a proposta do projeto e o cronograma de atividades.

Ao final dessa ação, o gestor mostrou-se receptivo ao tema proposto e os professores demostraram apoio e interesse em incluir a temática em seus planos de aula, visto que havia relatos de iniciaçáo precoce ao tabaco e outras drogas entre os escolares.

Entende-se que para a concretização do objetivo final desse projeto era de fundamental importância o fortalecimento entre as parcerias, tendo como base o diálogo entre os atores envolvidos no processo. E as contribuiçôes são, ou devem ser, ensino e serviço, para ambas as instituiçóes se beneficiarem com a integração.

O segundo momento foi realizado com os pais e/ou responsáveis dos alunos do turno vespertino. Nessa etapa, os acadêmicos do projeto elaboraram convites (Figura 1) que foram entregues com antecedência aos pais e/ou responsáveis para que estes participassem de uma reuniáo 
na escola. Estiveram presentes cerca de 60 pais e/ou responsáveis, que ficaram atentos à explicação e demostraram interesse pelas atividades do tema proposto, sendo evidenciado tal fato pelos questionamentos durante a explanação da temática.

Figura 1 - Convite para os pais e/ou responsáveis dos alunos do $6^{\circ}$ ao $9^{\circ}$ ano

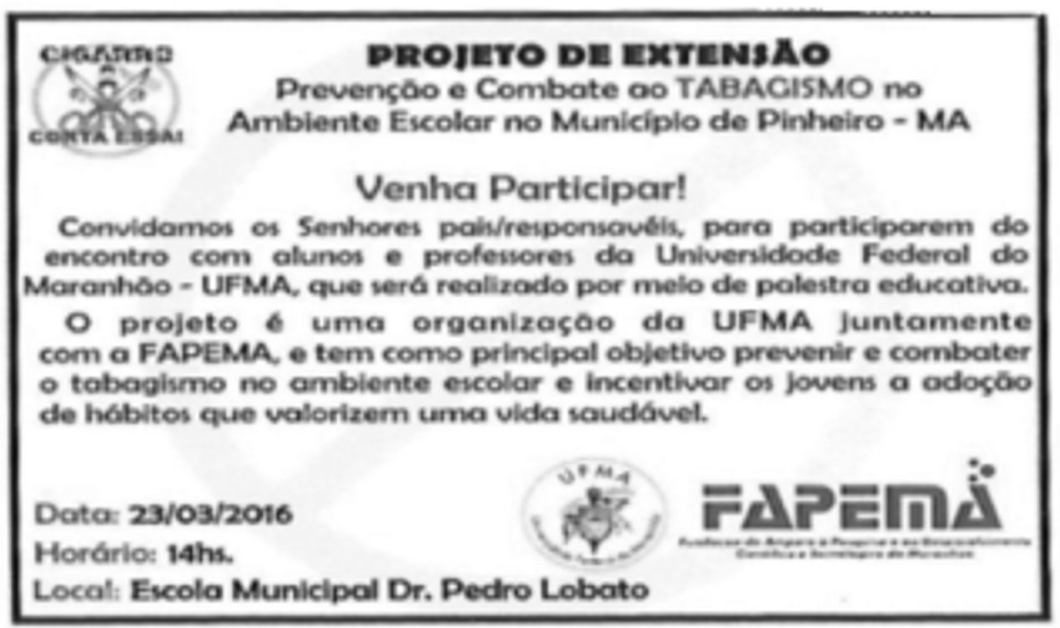

Fonte: Acervo do projeto (2016).

Sabe-se que a família é um lugar privilegiado para a promoção da educação. Mesmo que o jovem passe a conviver mais em outros ambientes - como escolas e clubes - é no seio da família que os valores morais e os padróes de conduta são incutidos. Assim, é importante que os programas de prevenção ao tabagismo incluam intervençóes junto à família e comunidade, visando, assim, prevenir o consumo de drogas não só ao nível da escola, mas ao nível de toda a comunidade (GUIMARÃES; OKABE; SCARINCI, 2017).

Dando continuidade ao projeto, a terceira etapa objetivou sensibilizar os alunos da escola sobre a temática "tabagismo" por meio da realização de diversas atividades educativas na escola. Essas ações foram desenvolvidas de forma multidisciplinar, cabendo aos acadêmicos abordarem os aspectos clínicos em relação aos efeitos do tabagismo no organismo e seus malefícios à saúde.

É importante ressaltar que o conteúdo abordado nessa atividade conceituou o tabagismo, os componentes do cigarro e também 
elencou as consequências de seu uso para a saúde, no que tange os aspectos morfológico e fisiológico dos pulmóes do fumante crônico. Desse modo, foram elucidadas consideraçóes importantes sobre fumantes passivos, bem como reforçadas medidas preventivas, por meio de estratégias como atividades esportivas e culturais voltadas para a modificação do ambiente que buscaram potencializar atitudes saudáveis, oferecendo alternativas contra o uso de drogas.

Nessa etapa, foram utilizadas apresentações em multimídia (vídeo educativo, slides) adaptadas à idade e ao conhecimento prévio do público, verificado antecipadamente por meio do pré-teste (questionário). Para a avaliação dessa intervenção foi realizado um Quiz para identificar fragilidades acerca do conteúdo e uma roda de conversa para sanar as dúvidas ainda existentes e aprofundar o tema abordado. Participaram desta intervenção $75 \%$ dos escolares.

É importante observar que antes da aplicação da intervenção, a maioria dos escolares demonstrou certa noção sobre os malefícios do cigarro à saúde do fumante e um número considerável discordou da proibição de fumar em lugares fechados. Ao final da etapa, já com a roda de conversa, a equipe executora pôde aprofundar esclarecimentos sobre o fumante passivo e os benefícios de um ambiente livre do tabaco.

É exposto, na literatura, que apesar dos adolescentes terem conhecimentos sobre os riscos que supóem o consumo de cigarro e seus derivados, seus hábitos parecem ser contrários. Além disso, os hábitos adquiridos nessa fase da vida costumam ser mantidos na idade adulta e são difíceis de modificar, levando à morbidade e mortalidade precoces. Assim, o desenvolvimento de comportamentos de proteção à saúde na adolescência pode ter um efeito positivo duradouro nas etapas seguintes da vida (MURTA et al., 2009).

Simultaneamente à terceira etapa, ocorreu a quarta etapa, uma vez que as duas estavam correlacionadas. Enquanto o ACS e os acadêmicos de medicina e enfermagem foram à escola para levar informaçôes e ideias, elaborou-se o planejamento e execução de outras açôes e atividades previstas no projeto de extensão. Sendo assim, foram realizadas atividades complementares propostas que contaram com acompanhamento dos professores da escola, além da equipe executora. Foram organizadas as seguintes atividades: (1) concurso de redação; (2) atividade lúdica como "corrida de saco"; (3) atividade lúdica como 
"passa ou repassa", contendo questionamentos sobre o tabagismo.

Com a gincana de perguntas e respostas ("passa ou repassa”) foi possível verificar o nível de entendimento e esclarecimento dos alunos quanto à temática, além de ter sido reforçada a importância da qualidade de vida e da adoção de hábitos saudáveis para possibilitar melhores níveis de saúde em todas as fases da vida.

É importante informar que cada integrante da equipe vencedora recebeu um kit escolar contendo estojo, lápis, borracha e caneta e as turmas vencedoras ganharam um troféu.

Os resultados obtidos ao fim da quarta etapa ressaltam que é importante que os programas educacionais antitabagismo sejam incentivados dentro das escolas, para que os alunos recebam orientação e ajuda profissional, sobretudo para os que querem deixar de fumar. A procura por serviços de saúde especializados, fora do ambiente escolar, pode acarretar em aumento do absenteísmo escolar e ainda dificultar o acesso e a adesão dos adolescentes aos programas (THOMAS; MCLELLAN; PERERA, 2013; 2015;).

A aproximação efetiva entre a formação profissional e a educação em saúde representou inúmeras possibilidades de articulaçáo entre o saber e o fazer, o que possibilitou aos acadêmicos uma vivência única e transformadora do processo de formação, pois tiveram a oportunidade de vivenciar uma realidade do dia a dia do trabalho em saúde, ao se deparar com situaçóes concretas sobre as quais eles poderão intervir e exercendo seu futuro papel como profissionais de saúde.

Por fim, foi realizada a quinta etapa por meio da avaliação do projeto, com o objetivo de verificar o cumprimento das metas estabelecidas no início da execução do mesmo. Nessa fase, verificou-se que 75\% dos alunos, do $6^{\circ}$ ao $9^{\circ}$ ano, foram sensibilizados e capacitados para a temática do Tabagismo. Supóe-se que os demais alunos faltaram às aulas nos dias da aplicaçáo do questionário pré-teste e da atividade realizada pela equipe executora do projeto, em sala de aula. Sabe-se também que $70 \%$ dos professores do $6^{\circ}$ ao $9^{\circ}$ ano do turno vespertino foram atendidos no projeto, pois os demais náo se encontravam na escola no momento da atividade. Além disso, efetivou-se a sensibilização com $100 \%$ dos coordenadores/diretores do turno vespertino, ultrapassando assim, a meta inicial. 
Dado o exposto, a avaliação dos discentes bolsistas do projeto pode ser expressa pelas mensagens abaixo:

A experiência de participar desse projeto foi única e enriquecedora, onde podemos colocar nossos conhecimentos da academia na prática levando informaçōes, tirando dúvidas, e acima de tudo prevenindo muito desses jovens venham adquirir o hábito do tabagismo [...], daí a importância desses projetos que impactam na cultura e política do tabaco. (DISCENTE BOLSISTA 1).

A participação no projeto foi de suma importância em minha vida acadêmica. Pude articular conhecimentos prévios com aqueles que busquei adquirir em cada etapa, podendo levar informaçóes aos funcionários em geral, diretor, professores, agentes administrativos, porteiros e serviços diversos alcançando principalmente pais e alunos, pois estes serão disseminadores de bons hábitos. (DISCENTE BOLSISTA 2).

Dentre as contribuições que a extensão proporciona, uma delas é a viabilização de uma formação universitária mais crítica, na qual os acadêmicos podem vivenciar situaçóes que possam ser aplicadas, futuramente, na área de atuação, em que essas experiências têm caráter ampliado, extrapolando os moldes tradicionais de formação profissional (NOBRE et al., 2017).

Tencionando que os resultados do projeto fossem divulgados de maneira mais abrangente, foi distribuído, ao fim da quinta fase, um boletim informativo. Esse material foi entregue aos alunos, professores, diretores e também aos pais presentes nesse momento de avaliação para que pudessem levar um exemplar para casa. Após a apresentaçáo dos resultados, os alunos da escola ouviram, atentamente, os depoimentos de dois ex-usuários de tabaco, álcool e outras drogas que estão em acompanhamento e tratamento em uma comunidade terapêutica da região. 
Em virtude do que foi exposto, destaca-se que a escola é um espaço privilegiado que proporcionou o encontro entre a educação e a saúde, e também um espaço de relaçôes favoráveis para a promoção da saúde pelo viés da educaçáo integral e da convivência social uma vez que estudos do Ministério da Saúde e do Instituto Nacional de Câncer comprovam que o uso inicial do tabaco predomina em idade escolar, por isso quanto mais cedo os jovens tomarem conhecimento dos riscos relacionados ao uso do tabaco e seus derivados menor a probabilidade de iniciaçáo do uso do fumo pela falta de conhecimento (BRASIL, 2015).

\section{CONSIDERAÇÕES FINAIS}

Tendo em vista os aspectos já mencionados, ressalta-se que a experiência vivenciada ao longo do projeto, proporcionou o desenvolvimento de estratégias para prevenção do início precoce do tabagismo, alertando adolescentes escolares sobre os malefícios do cigarro bem como sobre outros aspectos da saúde.

Sendo assim, o processo de construção dessa ação, que integra ensino-serviço, possibilitou diferentes aprendizagens no processo de formação para o Sistema Único de Saúde (SUS). No que concerne à Universidade, investir na extensão aproxima os sujeitos, oportuniza a imersão mais estreita da academia à realidade social local.

Dado o exposto, na condiçáo de graduandos dos cursos de Medicina e Enfermagem, buscou-se também, além do aprimoramento do currículo, a aquisição de conhecimentos acadêmicos e humanos, por meio da experiência em uma regiáo carente e com poucos recursos, na baixada maranhense.

É de suma importância ressaltar que a metodologia participativa com a comunidade e sua aceitaçáo oportunizou aos acadêmicos a construção de conhecimentos horizontais. Por meio do projeto, foi possível aliar a teoria à prática, sensibilizando e levando conhecimentos relacionados aos malefícios do tabagismo a adolescentes, pais, professores e funcionários em geral, através de atividades teóricas e práticas que incluíram uma exposição dialógica do tema e priorizaram o compartilhamento do conhecimento sobre tal hábito. 
Outro ponto importante foi que essas açôes contribuíram para o amadurecimento e a criatividade dos profissionais envolvidos nas açóes propostas. Enfatiza-se a importância dos profissionais de saúde e educação buscarem intervençôes a exemplo da compartilhada nessa experiência, a fim de sensibilizar os adolescentes em idade escolar sobre os riscos causados pelo uso do tabaco, minimizando com isso a possibilidade da iniciação precoce do uso dos mesmos pela desinformação.

Diante dos resultados obtidos, percebe-se que foram utilizadas estratégias efetivas para a compreensão dos objetivos propostos pelo projeto, uma vez que a populaçáo atendida se mostrou receptiva e participativa durante as atividades realizadas e, de modo geral, avaliouas como positivas.

Assim, conclui-se que atividades extensionistas com finalidade educativa realizadas no ambiente escolar precisam continuar sendo evidenciadas, tendo em vista que experiências exitosas podem ser (re) produzidas por outras instituiçóes com perfil semelhante.

\section{AGRADECIMENTOS}

À Fundação de Amparo à Pesquisa e ao Desenvolvimento Científico e Tecnológico do Maranhão - FAPEMA e à Universidade Federal do Maranhão (UFMA).

\section{REFERÊNCIAS}

BARANKIN, T. Aperfeiçoar a resiliência de adolescentes e suas famílias. Adolesc \& Saúde, Rio de Janeiro, v. 10, n. 2, p. 17-22, 2013, maio 2013. Disponível em: <http://www.adolescenciaesaude. com/detalhe_artigo.asp?id=401\#>. Acesso em: 10 jan. 2018.

BARRETO, S. M. et al. Experimentation and use of cigarette and other tobacco products among adolescents in the Brazilian state capitals (PeNSE 2012). Rev. bras. epidemiol, São Paulo, v. 17, supl. 1, p. 62-76, 2014. Doi: http://dx.doi.org/10.1590/18094503201400050006 . 
BORRACI, R. A.; MULASSI, A. H. Tobacco use during adolescence may predict smoking during adulthood: simulation-based research. Arch Argent Pediatr, v. 113, n. 2, p.106-12, abr. 2015. Doi: http:// dx.doi.org/10.1590/S0325-00752015000200006.

BRASIL. Ministério da Saúde. Secretaria de Atenção à Saúde. Departamento de Atenção Básica. Instrutivo PSE. Brasília: Ministério da Saúde, 2011. Disponível em: <http://189.28.128.100/dab/docs/ legislacao/passo_a_passo_pse.pdf>. Acesso em: 12 maio 2018.

- Ministério da Saúde. Programa Saúde na Escola. Caderno do gestor do PSE. Brasília: Ministério da Saúde; Ministério da Educação, 2015.68 p.

BUCHELE, F; COELHO, E. B. S.; LINDNER, S. R. A promoção da saúde enquanto estratégia de prevenção ao uso das drogas. Ciênc Saúde Coletiva, Rio de Janeiro, v. 14, n. 1, p. 267-273, fev. 2009. Doi: http://dx.doi.org/10.1590/S1413-81232009000100033.

FIGUEIREDO, V. C. et al. ERICA: smoking prevalence in Brazilian adolescentes. Rev Saúde Públ., São Paulo, v. 50, supl. 1, 12s, 2016. Doi: http://dx.doi.org/10.1590/S01518-787.2016050006741.

GUIMARÃES, A. B. P.; OKABE, I.; SCARINCI, I. C. A influência da família na iniciação e não utilização de produtos derivados do tabaco: diferenças de gênero. Espaço para a Saúde, Londrina, v. 18, n. 2, p. 70-76, dez. 2017. Doi: http://dx.doi.org/10.22421/1517$7130.2017 \mathrm{v} 18 \mathrm{n} 2 \mathrm{p} 70$.

IBGE - INSTITUTO BRASILEIRO DE GEOGRAFIA E ESTATÍSTICA. Coordenação de População e Indicadores Sociais. Pesquisa nacional de saúde do escolar: 2015. Rio de Janeiro: IBGE, 2016. 132 p.

JHA, P.; PETO, R. Global effects of smoking, of quitting, and of taking tobacco. N Engl J Med., v. 370, p. 60-68, jan. 2014. Doi: http://dx.doi.org/10.1056/NEJMra1308383.

MURTA, S. G. et al. Prevenção primária em saúde na adolescência: avaliação de um programa de habilidades de vida. Estudos de Psicologia, Natal, v. 14, n. 3, p. 181-189, set-dez. 2009. Doi: http:// dx.doi.org/10.1590/S1413-294X2009000300001. 
NOBRE, R. de S. et al. Vivenciando a extensão universitária através de açôes de educação em saúde no contexto escolar. Rev. APS, Juiz de Fora, v. 20, n. 2, p. 288-292, abr.-jun. 2017. Disponível em: $<$ https://aps.uff.emnuvens.com.br/aps/article/view/2616>. Acesso em: 10 mar. 2018.

SANTANA, S. de M. et al. A eficácia dos programas de prevenção em contexto escolar: uma revisão empírica da literatura. Revista de Psicologia da Criança e do Adolescente, Lisboa, v. 7, 1-2, p. 449463, 2016. Disponível em: <http://revistas.lis.ulusiada.pt/index.php/ rpca/article/view/2425/2584>. Acesso em: 9 out. 2017.

SMALLEY, S. E.; WITTLER, R. R.; OLIVERSON, R. H. Adolescent assessment of cardiovascular heart diseases risk factor attitudes and habits. J Adolesc Health, v. 35, n. 5, p.374-379, nov. 2004. Doi: http://dx.doi.org/10.1016/j.jadohealth.2004.01.005.

THOMAS, R. E.; MCLELLAN, J.; PERERA, R. School-based programmes for preventing smoking. Cochrane Database Syst Rev, v. 30, n. 4, abr. 2013. Doi: http://dx.doi.org/10.1002/14651858. CD001293.pub3.

. Effectiveness of school-based smoking prevention curricular: systematic review and meta-analysis. BMJ Open, v. 5, n. 3, 2015. Doi: http://dx.doi.org/10.1136/bmjopen-2014-006976.

WHO - World Health Organization. WHO report on the global tobacco epidemic, 2017: monitoring tobacco use and prevention policies. Geneva: WHO, 2017. Disponível em: <http://apps.who. int/iris/bitstream/handle/10665/255874/9789241512824-eng.pd f;jsessionid=77FD7A9443E83AD823F310041CE01DC5?sequen ce $=1>$. Acesso em: 15 maio 2018 .

Submetido em 22 de maio de 2018.

Aprovado em 6 de julho de 2018. 